\title{
Continuing the Discourse of Women in Information Technology: A South African Perspective
}

\author{
Hendrik W. Pretorius I Tendani Mawela' \\ Ian Strydom ' Carina de Villiers' Roy D. Johnson ${ }^{2}$
}

' Department of Informatics, University of Pretoria, Pretoria, South Africa.

${ }^{2}$ Gordon Institute of Business Science, University of Pretoria, Sandton, South Africa.

\section{Corresponding author:}

Hendrik W. Pretorius, University of Pretoria, Department of Informatics, Lynnwood Rd. \& Roper St., Pretoria 0002, South Africa.

E-mail: Henk.Pretorius@up.ac.za

\begin{abstract}
Currently, there is a worldwide decline in the participation of women in the information technology (IT) profession and education. This article continues the existing discourse on women in IT by discussing the South African domestic and IT work environments. The aim is to understand whether South African women experience similar levels of career problems in the IT industry as their international counterparts. Using critical interpretive analysis, we used the experiences of 48 women working in the private sector IT firms to investigate not only what attracts women in South Africa to the IT industry but also what discourages them from following a career in this field. The data were collected by means of an anonymous online questionnaire consisting of open- and close-ended
\end{abstract}


questions. This study provides an insight into the impact of domestic influences on women in the IT industry in South Africa. It also contributes to communities, such as, feminists, academia, practitioners, or governments, in the creation of an emancipation theory or a series of interventions to improve the situation for women in the South African IT industry.

\section{Keywords}

Gender, women, IT, South African, careers, emancipation theory

\section{Introduction}

Information technology (IT) is one of the most important industries for any nation in the world. It facilitates global communication, international trade opportunities, and support mechanisms for domestic and international services. It is a global business and economic enabler (Huang \& Trauth, 2006; Irwin, 2000; Nielsen, von Hellens, \& Beekhuyzen, 2005; Peppard, 1995; Trauth, Quesenberry, \& Huang, 2008). Besides being an enabler, the IT industry also has strategic importance in the world of business. And it is through this strategic role that it has become allpervasive (King, 2006).

The under-representation of high-achieving women (school, higher education, and industry) in the IT industry in many parts of the world remains a challenge (Holth, Almasri, \& Gonäs, 2013; Hunter, 2012; Lewis, Lang, \& McKay, 2007; Trauth \& Quesenberry, 2006).

This is also the case for South Africa (SA), where economic and physical securities (survival) are more important than the quality of life and self-expression. SA is classified as one of the poorest countries of the world, with a gross national product (GNP) of less than USD 2000 per capita in 2001 (wealthy countries had a GNP of more than USD 15,000 per capita in 2001). South Africans in general have low trust in people, are traditional (rather than secular rational), with a strong belief in God, national pride, and authority. SA also has one of the world's highest rates of inequality and hosts a diverse range of cultures that include 11 official languages.

We tackle the under-representation of women in the IT industry through four sections, starting with literature review, the research approach used for this study, data collection, and a discussion of our findings. 


\section{Literature Review}

Ramsey and McCorduck (2005) found that the proportion of women in the IT industry had declined from 40 percent in 1986 to 29 percent in 1999. Furthermore, the Information Technology Association of America (ITAA) in 2004 indicated that the US IT workforce is only represented by 32.4 percent of women (globally, it has the largest proportion of women in the IT sector), a fall of approximately 9 percent from 1996 (Trauth et al., 2008). Currently, this figure meets around 25 percent (Bohr, 2013). In Canada, it is reported that women constitute 50.4 percent of the country's population and 47.2 percent of the total employed workforce. However, the number of women in the IT sector is pegged at 21 percent (Faisal, 2012). In India, women make up only 14 percent of the IT industry workforce (Pande, 2006). In Europe too, men far outnumber women in IT professions. In the UK, women hold approximately 15 percent of computing positions, similar to proportions in the European Union (Hunter, 2012). In Australia, women only represent 19 percent to 25 percent (February 2011, 24.1 percent; February 2012, 19.7 percent) of the total IT workforce (Australian-Computer-Society, 2012; Hunter, 2012; Staehr, Byrne, \& Bell, 2006). In 2012, studies in New Zealand showed similar results (Hunter, 2012). In addition, studies in New Zealand indicate that women are remunerated less than their male counterparts (a gap of 23 percent) in the IT industry (Belgorodskiy, Crump, Griffiths, Logan, Peter, \& Richardson, 2012; Hunter, 2012).

With the dot.com crashes, the decline of women in IT has been even more significant. Even with the revival of job opportunities (which shows that IT is still one of the most leading employment sectors) students registering for courses in IT at universities in Australia were down by 30 percent to 40 percent. Women in engineering and IT are still regarded as an equity group in Australia, where targets of 40 percent plus were unmet. Similar findings are reported in the USA (Hunter, 2012; Nielsen et al., 2005; Ramsey \& McCorduck, 2005). Studies show that the under-representation of women in IT is a worldwide phenomenon (Huyer, 2005; Pretorius \& de Villiers, 2009; Rosser, 2005; Sanders, 2005). However, recent research (Adam, Bauer, \& Baichoo 2003; Fan \& Li, 2004; Lagesen, 2008; Lee, 2003; Shashaani \& Khalili, 2001; Varma, 2009) indicates that the number of women in IT education is increasing in several non-Western countries, such as, Iran, Hong Kong, Mauritius, Taiwan, Malaysia, and India. Varma (2009), for instance, shows how strong mathematical training in India makes 
female students feel confident about their computing skills in contrast to American students. Similarly, Adam et al. (2003) demonstrate how under specific cultural and environmental conditions, women fit well into computer science in Mauritius.

South Africa also faces the challenge of the under-representation of women in IT education and careers (Dlodlo, Mvelase, \& Krause, 2010). The country has a population of more than 51 million, of which women constitute 51.3 percent (STATSSA, 2012). However, a review of IT enrolments in higher educational institutions does not reflect their numbers. Kirlıdog and Zeeman (2011) found that the number of women enrolling in IT courses is almost half that of their male counterparts. One of the leading universities in the capital of SA has seen the number of female students doing BCom (Informatics) from the School of IT falling steeply from 58 in 2000 to 14 in 2012 . Needless to say, this decline will be reflected in the number of women in the IT industry in future.

In SA, gender equality across all sectors of society is supported by the Constitution. The South African government even established a department dedicated to drafting a women empowerment and gender equality policy and bill (DWCPD, 2012). In addition, the government enforces the empowerment of women through the Broad Based Black Economic Empowerment (BBBEE) Act and the Information and Communications Technology (ICT) Sector Charter in companies that recognize women as a designated group (DTI, 2012; ICT-EWG, 2004). However, the underrepresentation of women in the IT industry in general still highlights a global problem in the IT domain for both practice and research. This study therefore set out to focus on the impact of gender on the domestic and IT work environments of women in SA.

IT and gender research in general build on two inherently different approaches. The first approach holds that men and women are by nature fundamentally different. The second approach believes that gender differences are socially constructed (Nielsen et al., 2005). This study builds on the latter approach, which propagates that gender differences are socially constructed and culturally shaped (Li \& Kirkup, 2007; Trauth et al., 2008). Several studies support this approach. A study by Ecevit, Gündüz-Hoşgőr, and Tokluoğlu (2003) in Turkey reveals that the emphasis on gender equality and the political ideology of the country play an important role in the high percentage of women in the Turkish IT sector. Hersch (2000) further concludes that the increase of women in engineering careers in Eastern Europe can be attributed to economic, political, and cultural influences and the need for more 
engineers in these countries. However, Minguez (2005) illustrates how men, as the traditional breadwinners, have a negative impact on women's participation in the IT sector in Spain. According to Lewis et al. (2007), men and women also have different experiences and interactions with the science, engineering, and technology education (SET) curriculum and teaching environments. This study therefore does not categorize women and men differently, but investigates how women respond to the IT industry as a socially constructed male-dominant domain (Moore, Griffiths, Richardson, \& Adam, 2008).

It is important to identify the range of connotations associated with the IT industry to understand its context better (see Table 1).

Table I. Connotations Associated with the IT Industry

\begin{tabular}{ll}
\hline Connotation & Description \\
\hline $\begin{array}{l}\text { Continuous } \\
\text { learning and } \\
\text { change }\end{array}$ & $\begin{array}{l}\text { The IT industry is an ever-changing technological industry } \\
\text { that requires continuous learning and long working hours } \\
\text { (Nielsen et al., 2005; Pretorius \& de Villiers, 2009; Ramsey }\end{array}$ \\
\& McCorduck, 2005). \\
Chaos & $\begin{array}{l}\text { Many IT professionals associate the IT industry with chaos } \\
\text { because of constant change and information overload } \\
\text { (Nielsen et al., 2005; Pretorius \& de Villiers, 2009). }\end{array}$ \\
Challenging & $\begin{array}{l}\text { The ever-changing IT industry creates daily challenges } \\
\text { (Crump, Logan, \& Mcllroy, 2007; Ramsey \& McCorduck, }\end{array}$ \\
& 2005).
\end{tabular}

Tiring/burnout Long working hours are required to prevent falling behind, which can be tiring and eventually cause burnout (Nielsen et al., 2005; Pretorius \& de Villiers, 2009).

Male-dominated The world of IT is a male-dominated industry that socially culture that shapes technology as masculine

Family-work balance

IT requires more task-orientated, logical, functional skills rather than people skills shapes technology as inherently masculine (Brimacombe \& Skuse, 2013; Kuntjara, 2002; Nielsen et al., 2005; Pretorius \& de Villiers, 2009; Ramsey \& McCorduck, 2005).

The amount of hours required in the IT industry allows for less time to be with the family (Nielsen et al., 2005; Pretorius \& de Villiers, 2009).

The world of IT is seen as logical, functional (positivistic) rather than one of emotions or one where there is much reliance on people skills (Pretorius \& de Villiers, 2009; Ramsey \& McCorduck, 2005). 


\begin{tabular}{ll}
\hline Connotation & Description \\
\hline Traveling & $\begin{array}{l}\text { The IT sector requires professionals to travel (Pretorius } \\
\text { \& de Villiers, 2009; Ramsey \& McCorduck, 2005). }\end{array}$ \\
$\begin{array}{l}\text { Male-dominant } \\
\text { communication }\end{array}$ & $\begin{array}{l}\text { Currently, the IT sector is dominated by male stereotype } \\
\text { communication (Kuntjara, 2002; Pretorius \& de Villiers, }\end{array}$ \\
culture & $\begin{array}{l}\text { 2009; Ramsey \& McCorduck, 2005). } \\
\text { High stress levels }\end{array}$ \\
& $\begin{array}{l}\text { High stress levels are caused by a combination of factors, } \\
\text { such as, the ones listed in this table (Nielsen et al., 2005). }\end{array}$ \\
\hline
\end{tabular}

\section{Research Approach}

The research objectives of this study are formulated in the following research questions:

1. How does gender impact the domestic and IT work environments of South African women?

2. What attracts South African women to the IT industry?

A critical interpretive research approach was adopted for this study. As per the interpretive research paradigm, social life is based on socially constructed meaning (Chen \& Hirschheim, 2004; Jones \& Nandhakumar, 1997; Klein \& Myers, 1999; Walsham, 1995; Webber, 2004). For critical interpretive researchers, the goal of research is to actively challenge interpretations and values to bring about change (Creswell, 2003). This is why the critical interpretive approach is sometimes known as the transformative paradigm.

Critical discourse analysis (CDA) of Norman Fairclough (2010) was used to analyze the data collected from the various participants. CDA does not limit its analysis to specific structures of text or talk as is the case of discourse analysis, but systematically relates these to structures of the broader sociopolitical context (Fairclough, 2010; Wodak, 2001). The framework combines various levels of data analysis interpretations (Karreman, 2000). In the first analysis (the micro-level), for example, the analyst only considers various aspects of the textual analysis. Then, at a later stage (the meso and macro levels of analysis), the analyst takes into account the broad, societal currents that are affecting the text being studied. In other words, the sociopolitical context of interpretation broadens at every level of analysis (Fairclough, 2010; Karreman, 2000). 
During the first phase of the analysis, the authors analyzed and investigated the data collected from the 48 respondents, who were women employees of private sector IT companies in SA. The focus at this stage was to understand (interpret) the responses (the data) at the micro-level, directly from the perspective of those who experienced it, without considering the sociopolitical context.

In the second phase of the analysis, the responses (data) were grouped into wider socially constructed themes (the meso and macro levels of the context were considered) that acted as a framework to discuss and question the root causes of the problem, specifically from a South African perspective. The discussion identified synergies that could be used for improving the situation of women in SA. In this phase, the authors also discussed the factors that attracted South African women to the IT industry. This study aims to gain more insight into the problems South African women experience in the IT industry.

A critical analysis questionnaire was developed from the factors identified (in Table 2), as the causes for the under-representation of women in the IT industry internationally.

Table 2. A Critical Analysis of the Factors Identified that Cause Underrepresentation of Women in the IT Industry

\begin{tabular}{ll}
\hline Identified Factors & Critical Analysis Questions \\
\hline $\begin{array}{l}\text { I. Dualism: Change as } \\
\text { challenge versus change } \\
\text { as chaos }\end{array}$ & I.I $\begin{array}{l}\text { Can change in the IT industry be } \\
\text { experienced by South African women as } \\
\text { positive and challenging, rather than as } \\
\text { negative and chaotic? }\end{array}$ \\
I.2 How can the playing field be leveled to \\
make the challenges for South African \\
women similar to those for men? \\
2. $\begin{array}{l}\text { Can the traditional role of women in SA } \\
\text { (as a homemaker) be changed? }\end{array}$ \\
$2.2 \begin{array}{l}\text { Can the culture of the IT industry change } \\
\text { to accommodate South African women } \\
\text { who have families? }\end{array}$ \\
$2.3 \begin{array}{l}\text { Are there other ways for South African } \\
\text { women who want to do as well in the } \\
\text { IT industry as their male counterparts, } \\
\text { to help them cope up with family } \\
\text { responsibilities? }\end{array}$
\end{tabular}




\begin{tabular}{|c|c|}
\hline Identified Factors & Critical Analysis Questions \\
\hline $\begin{array}{l}\text { 3. Women's perception of } \\
\text { the IT industry }\end{array}$ & $\begin{array}{l}\text { 3.I How can South African women's } \\
\text { perception of the IT industry be changed } \\
\text { to make it more attractive to them? }\end{array}$ \\
\hline $\begin{array}{l}\text { 4. The IT industry is a } \\
\text { male-dominated working } \\
\text { environment with }\end{array}$ & $\begin{array}{l}\text { 4.I Can the male-dominant IT culture be } \\
\text { changed to make it more attractive for } \\
\text { women in SA? }\end{array}$ \\
\hline $\begin{array}{l}\text { ingredients, such as, male- } \\
\text { dominant communication } \\
\text { that shapes technology as } \\
\text { inherently masculine }\end{array}$ & $\begin{array}{l}\text { 4.2 How can communication be changed } \\
\text { in the IT industry (including the South } \\
\text { African industry) for it to be acceptable to } \\
\text { both men and women? }\end{array}$ \\
\hline
\end{tabular}

\section{Data Collection}

Data were collected from 48 women working in the private sector IT industry in SA by means of an anonymous online questionnaire consisting of open- and close-ended questions. These women also shared the experiences of fellow women colleagues, who had left the IT industry or had changed jobs in the IT profession.

The respondents represent different IT professions, age ranges, levels of education, years of IT experience, marital status, and ethnical origins as described below:

1. IT Professions:

- Managerial IT positions (50 percent), IT analysis positions (16 percent), technical IT positions (15 percent), IT sales positions (4 percent), and other IT positions (15 percent).

2. Age ranges:

- 18-30 years (15 percent), 31-40 years (35 percent), 41-50 (40 percent), and $50+$ years (10 percent).

3. Levels of education:

- Grade 12 (9 percent), Bachelor's degree (25 percent), Honors degree (6 percent), Master's degree (10 percent), $\mathrm{PhD}$ degree (4 percent), other training after grade 12 (4 percent), and other education after grade 12 (42 percent). 
4. Years of IT experience:

- 0-2 years (8 percent), 3-5 years (2 percent), 6-10 years (21 percent), $11-20$ years (35 percent), and $20+$ years ( 34 percent).

5. Marital status:

- Single (27 percent), married (58 percent), divorced (15 percent), and women with partners ( 0 percent). Of these women, 71 percent have dependents.

6. Ethnic origin:

- Black (13 percent), White (65 percent), Asian-Indian ${ }^{1}$ (15 percent) and colored ${ }^{2}$ ( 7 percent).

In the online questionnaire, the women shared personal (domestic environment) and professional (work environment) reasons that make them leave the IT industry in SA. But they also described the reasons that made them stay.

\section{Findings}

\section{Change as Challenge or as Chaos?}

The interpretive analysis of the women's experiences in the IT industry internationally throws up two very important facts. The first is that the IT industry is demanding with regard to continuing education. The second is that women battle to find enough time to be able to keep up with the demanding IT industry especially if they have a family. The latter question is discussed in detail in the next section.

In the online survey, 87 percent of the South African women respondents indicated that they found the IT industry challenging rather than chaotic. The respondents indicated (58 percent) that the biggest challenge lay in finding time for the continuous education that is required to keep up with the ever-changing IT industry. Almost all the women agreed (97 percent) that the IT industry is demanding and requires constant education and time. Some of the respondents made the following observations:

Definitely. That is my biggest problem, I don't have the time to keep up to date with new training requirements as my family life is very important. 
The environment is ever changing. For me this is positive and challenging, but for people who are risk averse, it might feel the opposite.

An ever-changing environment. No day is ever the same. Clients are getting more technical so the job becomes more challenging forcing you to keep up with the latest trend.

Other factors that women in the South African IT industry experience, which makes the industry challenging are pressure/stress (4 percent) and the male-dominated environment that made their career growth extremely difficult (4 percent). Here are some comments from the respondents:

If something is going to go wrong, it usually does. There is no such thing as a quick smooth change. This puts a hell lot of pressure on the workers.

In the fast track times that we are living in, the high demands are not all rewarding and stressful to the body. Majority of projects fail and no lessons seem to be learned either.

Proving oneself in a male-dominated industry creates challenges to excel.

Sixty-one percent of the women respondents indicated that they have less time to spend on the IT industry than their male counterparts, while 31 percent did not have a definite answer. This can be attributed to family responsibilities shouldered by women. Kreitner and Kinicki (2004) present some interesting facts regarding the division of work done by women and men at home:

1. Preparation of meals: 50 percent of women and 9 percent of men,

2. Shopping for groceries: 51 percent of women and 7 percent of men,

3. Organizing activities of children: 61 percent of women and 3 percent of men,

4. House cleaning: 45 percent of women and 5 percent of men,

5. Attending a sick child: 51 percent of women and 9 percent of men.

These figures present a bleak picture of male involvement at home. Lewis et al. (2007) further report that male IT undergraduates report significantly more difficulty in balancing their time between study, work, and social activities. Adam, Howcroft, and Richardson (2004) support these facts by noting that in recent times there has been a greater focus on information as an organizational resource. This suggests that the time 
to manage information is also increasing. Many of us battle with information overload in our current work environments. South African women, therefore, can definitely argue that they have much less time than their male counterparts as they have to juggle a very demanding job in the IT industry and family responsibilities at home (Pretorius \& de Villiers, 2009). To revisit the critical interpretive analysis questions (Table 2): Can change in the IT industry be experienced by South African women as positive and challenging, rather than negative and chaotic? How can the playfield be equaled to make the challenges for South African women similar to those for men?

Yes, South African women definitely view the South African IT industry as challenging, rather than chaotic. There are some challenges that need to be addressed as indicated in this section.

\section{Work versus Family?}

Family values are the belief in the importance of family and who should play key family roles (e.g., housekeeping and income earning). Lack of similar values among family members can lead to work-family conflict. There are two types of conflicts, namely, work interference with family or family interference with work and both of these can have a negative impact on either work or family. Satisfaction tends to be higher for those who live according to their values (Kreitner \& Kinicki, 2004).

In the online survey, 82 percent of the women indicated that they experience work-family conflict. They complained of long demanding hours of work in order to perform well (29 percent), traveling (13 percent), and attending to family matters (15 percent). As stated in the words of some of the respondents:

It is constantly a challenge if I go for training. My children are young and ultimately suffer the price of my training and educating myself. I battle to get family to look after them whilst I am away.

I am a single mom and many times I have declined events regarding my children at school as I am away on business or travelling, it is part of the requirements regarding my job. My competitors are either single women or men who have a stay at home wife assisting them.

My husband says all I ever talk about is work. My kids say that I am impatient, or just don't listen to them. The reason is I am either so mentally drained when I get home, or I am worrying about something that I know needs to get done at work as soon as possible. 
Should needs arise regarding family and home during working hours, women are far more likely to be called upon to step in while men are less "available."

A study by Medeiros (2005) in Brazil found that improving the participation of women in the IT workforce hinges on the family. Women experience work-family conflict much more than men because of social norms. Our survey indicated that 19 percent of women see themselves as traditional homemakers, 13 percent of the women regards themselves as career women, while 68 percent shared the responsibilities of homemaking with others. This brings us to the question: Can the traditional role of South African women - the one mainly responsible for homemaking - be changed?

If one looks at the question from a positivistic point of view, the answer is yes. Studies conducted by Adams et al. (2003) and Adams, Baichoo, and Bauer (2006) in Mauritius found rapid increase in enrolment of women in computer science (37 percent) and engineering (51 percent) from 1990 to 2003. The authors attributed it to the national culture where families place a high value on women taking up IT careers. Therefore, women can definitely break the social norm of being the homemaker, but the answer shortcuts many of the complexities experienced by women in their work-family context.

The philosophical viewpoint of "thrownness" can better explain their situation. This viewpoint states that a person (in our case women) is thrown into the world and has to face and accept the circumstances (context) into which she is thrown. To change these socially constructed circumstances depends on the context in which the women find themselves. Women in some Middle East countries, for instance, might even be punished with death for trying to break the socially constructed norms. In our survey, 37 percent of the women indicated that culture, religion, and ethnic origins play a role in work-family conflict. As stated by some of the respondents: "My husband comes from a very Afrikaans background where mother was at home looking after the kids. My cultural background encourages men to do the bare minimum in the home. This puts pressure on me as a woman. I have to earn money like a man and still be like a stay at home mom."

Women in Western countries might find it easier to share the traditional role of homemaking with men. Li and Kirkup (2007) argue that cultural factors play an important role in the relationship between women and IT. Similarly, Trauth et al. (2008) note that one should not only consider demographic differences but sociocultural and individual 
differences as well. Eidelman and Hazzan (2005, 2006), Hersh (2000), and Nielsen et al. (2005) further argue that the role of women, embedded in the culture of a society, influences their career choice in conjunction with sociocultural moderators. Religion, national culture, personal values, family values, and other socially constructed norms within a specific context can make it very difficult for women to break away from their traditional roles (Eidelmann \& Hazzan, 2005, 2006; Hersch, 2000; Minguez, 2005; Nielsen, von Hellens, Greenhill, \& Pringle, 1998; Pretorius \& de Villiers, 2009; Razavi \& Miller, 1995).

On the positive side, recent research shows that by integrating work with family and sharing income and homemaking responsibilities, it is possible for women and men to find satisfaction in both work and personal lives. Some of our respondents echoed these sentiments:

...my husband and I work as a partnership knowing that sometimes one will have to work longer. If the relationship was not so strong, we would have conflict, but we made a deal with each other, to give everything while you are in the moment, meaning that if you are working you give it you're all, best. When you are with the kids at home or on holiday, no work...

My husband and I are both Christians and have the same morals and values. We decide together what is best for the family and work from there.

Coming back to the analysis question: Can the culture of the IT sector change to accommodate South African women who have families?

Yes, there are definitely South African employers who promote a family-supportive philosophy. Our survey indicates that 68 percent of the South African employers will allow women to work from home, but mostly in the case of an emergency. Many employers are afraid that such a culture may collide with a culture that values hard work and long hours above all. This is in accordance with some of the responses we received from our survey:

I am a programmer manager and according to business perspectives needs to be at my office.

They prefer having us at the office all the time - micro management.

The question that follows is:

Are there other ways for South African women who want to do equally well in the IT industry as their male counterparts to help them cope with family responsibilities? 
Yes, there are examples of South African women who hired help to cope with family responsibilities and stand in for them when busy at work, but this is not always acceptable for all members of the family, which may lead to conflict (Ramsey \& McCorduck, 2005). It is also the opinion of the authors that "surrogate" 3 family members can cause problems of their own, but from a positivistic point of view, it offers a solution. Another route to explore is that of technology to alleviate work-family conflict. Evidence indicates that when women have access to IT facilities at home, they can substantially improve their lives and increase their incomes (Huyer, 2005). Our survey indicates that 18 percent of women make use of technology to work from home. In the survey, the respondents indicated that interconnectivity (typically a laptop and a 3G card), a mobile phone, and telecommuting are the most important and convenient technologies required to work from home.

\section{Women's Perception of the IT Industry}

Sixty-six percent of our respondents perceived the IT industry as functional, task orientated, abstract, procedural, and mathematical. Only 11 percent of them viewed the IT industry as softer, consisting of human skills and abilities. However, 58 percent said they would prefer to use both hard technical skills and softer human skills in the IT industry. Only 21 percent of the women preferred only harder technical IT skills, and only 18 percent said they would prefer softer IT skills.

IT is typically viewed by women as functional, logical, task-orientated, abstract mathematical, and technical, consisting of programming, building computers, and building networks, with none of these attracting many women, who are generally better with human, non-technical skills (Cohoon \& Aspray, 2006; Mahony \& Van Toen, 1990; Moore et al., 2008; Nielsen et al., 2005). The IT industry is further viewed as male dominated (Moore et al., 2008). This has ripple effects on other people with whom they have direct contact (i.e., family members). Wacjman (2004), Webster (2005), and Moore et al. (2008) further argue that the technologies around IT are socially shaped as masculine, because over time the culture of masculinity is coterminous with the culture of technology, which makes IT professions more unattractive for women. Moore et al. (2008) suggest that we should also ask women about their perceptions of their personal futures, notably in terms of their career. This brings us to the analysis question: How can South 
African women's perception of the IT industry be changed to make it more attractive for women?

A factor that can change the perception of women about the IT industry is proper education about the industry. The IT industry is diverse and consists of many non-technical and technical jobs (Nielsen, et al., 2005). It also involves jobs where "softer skills" (from the perspective of women) are required. An example is business analysis and project management, which require facilitation and people skills. Learners can be educated from an early stage on what IT is all about.

Lewis et al. (2007) reveal that current education systems are very ignorant of gender learning and questions (Adam et al., 2004; Adams et al., 2003). Lewis et al. (2007) further state that there has not been any professional review of the IT tertiary education sector in Australia with regard to cultural diversity because of the decline in gender balance. Special interventions are required to deal with the gender issues at hand (Quesenberry \& Trauth, 2012). Margolis and Fisher (2002) demonstrated in a study at Mellon University in the US how specific interventions can dramatically increase the number of female students who study computer science. Conell (2002) suggests that unless equity issues play an active role in both policy and practice within IT facilities, intervention programs will have a minimal benefit. Murphy and Whitellegg (2006) conclude that the reconstruction of a curriculum should be context driven and not content driven. It is well established that girls more than boys engage with learning and teaching when the curriculum is contextualized and relevance is clearly established (Boaler, 1997; Murphy \& Elwood, 1998).

\section{IT Industry as Male-Dominant Environment}

Stereotyping is judging someone based on our perception of the group to which he or she belongs. The problem with stereotyping is that one can stereotype inaccurately. In our survey, 82 percent of the respondents said that the South African industry has a masculine culture. They attributed it to the technical and male-friendly nature of the skills required in the IT industry ( 21 percent), and management teams that are dominantly male (11 percent) allowing fewer growth opportunities for women. The respondents said traditionally, IT is perceived as a male industry ( 8 percent) and leads to the exclusion of women from social networks in the IT industry, which is dominated by men 
(8 percent). In other words, women seldom feel part of the IT industry culture:

The masculine culture was inherited from previous generations. Women in IT today try their utmost to change the culture.

IT is perceived as "technical" and men are perceived as being better at technical matters than women.

Men are taken more seriously technically and most management is male and they operate differently.

On the whole IT is socially shaped as a masculine culture. It is mainly governed by men and very little women.

My experience is that men all go fishing or to the bar for drink, but as women this would not go down well so we are excluded.

Fifty-five percent (55 percent) of the women surveyed, indicated that they experience some form of gender discrimination in the IT industry. Major forms of discrimination against women include salaries (16 percent), promotions, especially to management level (13 percent), and skills set (16 percent). Responses from the respondents include:

We do not receive the same salaries (as men.) Women are paid much less. If you ask for salary banding information for specific job descriptions, it is withheld on purpose.

Yes, if it comes to promotion to management level.

Women are not as technical as young male geeks, and are therefore perceived to be stupid. "Soft stuff" like human use is not important to techies and engineers.

Returning to the analysis question:

Can the male dominant IT culture be changed to make it more attractive for women in South Africa?

Many countries are trying to make the IT industry more acceptable to women by introducing equity acts or measures (Nielsen et al., 2005; Ramsey \& McCorduck, 2005). Studies conducted by Adams et al. (2003, 2006) in Mauritius, for example, show that single-sex high school systems help girls to develop aptitude and interests toward technology in the absence of male peer pressure to conform to gender stereotypes about 
technology. In Turkey, where there is an emphasis on gender equality, women hold a higher share of computer-related occupations compared to other male-dominated occupations (Trauth et al., 2008). Although equity acts like these were introduced by many governments, the proportion of women in the IT industry still declined (Ramsey \& McCorduck, 2005). It seems that mere passing of policies and acts is not the real solution to the problem.

The only way to change the culture is to make women part of the IT industry (management, culture, equal earnings, and social networks) (Huyer, 2005). Wajcman (2004, p. 111) states “...unless women are in the engine rooms of technological production, we cannot get our hands on the levers of power."

Gender barriers and stereotypes need to be broken in SA. Relaxing socially constructed norms by encouraging the sharing of homemaking responsibilities between women and men will make it easier for SA women to participate in the IT industry. The culture can only change when women become part of the culture (Nielsen et al., 2005; Ramsey \& McCorduck, 2005). Wajcman (2004) further highlights the importance of imagining how different our socio-technical world might be if women had a greater involvement in the shaping of technologies, now and in the future.

As more and more South African women grow up with new technologies, which will form part of their everyday realities, the stereotyping of technology as a masculine domain and practice will fall away. This will break down gender barriers (Kuntjara, 2002). Trauth et al. (2008, p. 9) conclude by saying: " ... while the social status of women is improving and the gender gap is becoming narrower...there are still significant issues with respect to improving the participation of women in the IT workforce."

Lastly, women's perception of the IT industry should change. There are also non-technical, "softer" jobs (e.g., business analysis, lecturing, project management, etc.) which would suit many women better. How can communication be changed in the IT industry (including the South African Industry) for it to be acceptable for both men and women?

Communication differences between women and men in the IT industry are an interesting topic. Men's language is characterized as aggressive, assertive, full of confidence, matter-of-fact, and critical, while women's language is perceived as more polite, cooperative, submissive, sensitive, lacking in self-confidence, and passive. This is one of the gender barriers that need to be broken in the IT industry (Kreitner \& Kinicki, 2004; Kuntjara, 2002; Robbins, 1993). 


\section{What Attracts Women to the IT Industry?}

Most of the South African women respondents who took our survey indicated that intellectual stimulation (44 percent) keeps them in the IT industry. Other major attractions include good salaries (29 percent), flexible time and work environments ( 25 percent), job security (17 percent), and job satisfaction (10 percent). In the words of some of the respondents:

I believe that women that stay and do well in the industry are those with a passion for technology and analysis, those that do not see it as a "job" but a career and loves the hunt for solving problems. I stay because the industry is perfect for me and I love it.

The IT industry is very dynamic and intellectually challenging.

The pay is good.

IT most of the time have more flexible hours.

In general, women enjoy the challenges that the IT industry brings. They believe they can contribute to solving problems in this industry by bringing a different set of skills to the table.

\section{Conclusion}

This article builds on the international discourse about women in IT by performing a critical interpretive analysis of the South African situation. The aim is to find out whether South African women experience similar career problems in the IT industry as their international counterparts. The study indicates that South African women face strikingly similar challenges in terms of work and home environments.

First, women share a perception internationally and in SA that the IT industry is functional, logical, task orientated, consisting mainly of programming and building hardware (computers and networks). This detracts many women, who believe they are better with "softer," non-technical jobs and tasks, from pursuing the IT field. In other words, the diverse nature of the IT industry is not understood well by women.

This perception can be changed by educating women about the diverse nature of the IT industry, and by changing the education systems to create 
better opportunities for women in the IT sector. This might be easier said than done and may require more research.

Second, South African women too perceive the IT industry as being male dominated. One way to change this situation is for women to break the barriers of the male-dominated IT industry. This involves many aspects of the IT industry, such as, sociocultural factors, education, maledominated social networks, and executive management. More women in executive roles will contribute to making the IT industry more acceptable for women.

Third, women are hesitant to get involved in the IT industry due to its association with long hours and continuous learning. This is at odds with the traditional role of women as homemakers and often leads to workhome conflict. It can be very difficult for women to change this socially constructed norm, which is influenced by the cultural context. Women in the Western world typically have a better chance than women in the Middle East countries to change their situation due to more sympathetic social norms.

On the positive side, socially constructed norms are changing slowly. Men and women are becoming more equally responsible for income generation and homemaking. Research has proven that in situations where the socially constructed norms are relaxed, it is possible for both women and men to perform to the best of their capabilities, and find satisfaction in both work and personal lives.

Finally, in answering the secondary research question of this study, What attracts South African women to the IT industry?, it was found that South African women believe they bring a different set of skills for solving problems in the IT industry. Furthermore, they enjoy the challenges that the IT industry offers. Other attractions include flexibility to resolve issues that arise from work-family conflict as well as better remuneration. In conclusion, many women have a passion for the IT industry akin to their male counterparts. These women are attracted to technology, problem solving, and the dynamic and changing environment of the IT industry.

This study contributes to the current body of knowledge by providing insights into the impact of domestic influences on women in the IT industry in SA. The study further contributes to communities, such as, feminists, academia, practitioners, or governments in the creation of an emancipation theory or a series of interventions to improve the situation for women in the South African IT industry. However, more research needs to be conducted to provide a socio-economic, cultural, and political underpinning to women in the IT industry in SA. 


\section{Acknowledgment}

This journal article expands on research that was presented at the South African Institute for Computer Scientists and Information Technologists (SAICSIT) conferences that were held in Gauteng, SA, in October 2009, and in Limpopo, SA, in October 2010.

\section{Notes}

1. Asian-Indian is an ethnic label used in this study for people from Asian ethnic origins of which most (but not all) are actually from Indian ethnic origins.

2. Colored is an ethnic label for people of mixed ethnic origin. They possess ancestry from Europe, Asia and various Khoisan and Bantu ethnic groups of Southern Africa.

3. A term used for hired help who can assist families, especially women with family responsibilities. This may include domestic workers, nannies, family members, etc.

\section{References}

Adam, A., Howcroft, D., \& Richardson, H. (2004). A decade of neglect: Reflecting on gender and IS. Technology and Employment, 19(3), 222-240.

Adams, J.C., Bauer, V., \& Baichoo, S. (2003). An expanding pipeline: Gender in Mauritius. In the proceedings of ACM SIGCSE Conference (pp. 50-53). New York: ACM Press.

Adams, J.C., Baichoo, S., \& Bauer, V. (2006). Women embrace computing in Mauritius. In E.M. Trauth (Ed.), Encyclopedia of gender and information technology (pp. 1258-1266). Hershey, PA: Idea Group.

Australian-Computer-Society. (2012). Australian ICT statistical compendium. Sydney: Australian Computer Society Inc.

Belgorodskiy, A., Crump, B., Griffiths, M., Logan, K., Peter, R., \& Richardson, H. (2012). The gender pay gap in the ICT labor market: Comparative experiences from the UK and New Zealand. New Technology, Work and Employment, 27(2), 106-119.

Boaler, J. (1997). Experiencing school mathematics: Teaching style, sex and setting. Buckingham: Open University Press.

Bohr, B. (2013). Gender codes: Why women are leaving computing. The Information Society, 29(4), 252-253.

Brimacombe, T., \& Skuse, A. (2013). Gender, ICTs and indicators: Measuring inequality and change. Gender, Technology and Development, 17(2), 131-157.

Chen, W., \& Hirschheim, R. (2004). A paradigmatic and methodological examination of information system research from 1991 to 2001. Information Systems Journal, 14(3), 197-235.

Cohoon, J.M., \& Aspray, W. (2006). A critical review of the research on women's participation in postsecondary computing education. In J.M. Cohoon \& 
W. Aspray (Eds), Women and information technology (pp. 137-180). Cambridge, Massachusetts: MIT Press.

Conell, R.W. (2002). Gender. Cambridge: Polity Press.

Creswell, J.W. (2003). Research design: Qualitative, quantitative, and mixed methods approaches (2nd ed.). Thousand Oaks: Sage.

Crump, B.J., Logan, K.A., \& McIlroy, A. (2007). Does gender still matter? A study of the views of women in the ICT industry of New Zealand. Gender, Work and Organization, 14(4), 349-370.

ICT-EWG. (2004). The ICT charter [Online]. ICT Empowerment Working Group. Retrieved June 2013, from www.ictcharter.org.za/content/The\%20 ICT\%20BEE\%20Charter\%20Nov04.pdf

Dlodlo, N., Mvelase, P.S., \& Krause, C. (2010). Gender-based survey of learning styles of South African employees in ICT careers. Hawaii International Conference on Education. January 7-10, 2010, Hawaii, 15.

DTI. (2012). B-BBEE sector charters: The Department of Trade and Industry. Retrieved June 2013, from www.thedti.gov.za/economic_empowerment/ bee_sector_charters.jsp

DWCPD. (2012). Remarks by the minister of women, children and people with disabilities, Ms Lulu Xingwana, on the Debate on National Women's Day at the Joint Sitting of Parliament. In Department-of-Women-Children-andPeople-with-Disabilities (Ed.). Cape Town.

Ecevit, F.Y., Gündüz-Hoşgőr, A., \& Tokluoğlu, C. (2003). Professional women in computer programming occupations: The case of Turkey. Career Development International, 8(2), 78-87.

Eidelmann, L., \& Hazzan, O. (2005). Factors influencing the shrinking pipeline in high schools: A sector-based analysis for the Israeli high school system. In proceedings of the ACM SIGCSE conference (pp. 406-410). New York: ACM Press.

- (2006). The shrinking pipeline in high schools. In E.M. Trauth (Ed.), Encyclopedia of gender and information technology (pp. 1092-1098). Hershey, PA: Idea Group.

Fairclough, N. (2010). Critical discourse analysis: The critical study of language (2nd ed.). London: Routledge.

Faisal, S. (2012). Encouraging outlook for women in ICT sector leadership roles. Canada: ICTC-Information and Communications Technology Council. Retrieved August 2013, from http://www.ictc-ctic.ca/?p=7942

Fan, T.S., \& Li, Y.C. (2004). Gender issues and computers: College computer science education in Taiwan. Computers \& Education, 44, 285-300.

Hersch, M. (2000). The changing position of women in engineering worldwide. IEEE Transactions of Engineering Management, 4(3), 345-359.

Holth, L., Almasri, A., \& Gonäs, L. (2013). Career patterns for IT engineering graduates. Economic and Industrial Democracy, 34(3), 519-535.

Huang, H., \& Trauth, E.M. (2006). Cultural diversity challenges: Issues for managing globally distributed knowledge workers in software development. 
In P. Yoong \& S. Huff (Eds), Managing IT professionals in the Internet age (pp. 254-276). Hershey, PA: Idea Group.

Hunter, A. (2012). Locating women in the New Zealand computing industry. Journal of Applied Computing and Information Technology. 16(1), 1-9.

Huyer, S. (2005). Women, IT and the information society: Global perspectives and initiatives. In Proceedings of the international symposium on women and IT: Creating global transformation. New York: ACM Press.

Irwin, L. (2000). Gender inequalities in technology in developing nations: Females and computers in traditional cultures. Intercultural Education, 11(2), 195-200.

Jones, M., \& Nandhakumar, J. (1997). Too close for comfort? Distance and engagement in interpretive information system research. Information Systems Journal, 7(2), 109-131.

Karreman, D. (2000). Varieties of discourse: On the study of organizations through discourse analysis. Human Relations, 53(9), 1125-1149.

King, M. (2006). The corporate citizen: Governance for all entities. Johannesburg: Penguin Books.

Kırlıdoğ, M., \& Zeeman, M. (2011). Equity in South African higher education after apartheid. Technology and Society Magazine, IEEE, 30(1), 55.

Klein, H.K., \& Myers, M.D. (1999). A set of principles for conducting and evaluating interpretive field studies in information systems. MIS Quaterly, 23(1), 67-94.

Kreitner, R., \& Kinicki, A. (2004). Organisational behaviour (6th ed.). New York, NY: McGraw-Hill.

Kuntjara, E. (2002). Gender issues in information technology communication. 1998-2002 Isis International-Manila. Retrieved August 2013, from www. isiswomen.org

Lagesen, V. (2008). A cyberfeminist Utopia? Perceptions of gender among Malaysian women computer science students and faculty. Science, Technology, \& Human Values, 33(1), 5-27.

Lee, A.C.K. (2003). Undergraduate students' gender differences in IT skills and attitudes. Journal of Computer Assisted Learning, 19(4), 488-500.

Lewis, S., Lang, C., \& McKay, J. (2007). An inconvenient truth: The invisibility of women in IT. Australian Journal of Information Systems, 15(1), 59-76.

Li, N., \& Kirkup, G. (2007). Gender and cultural differences in Internet use: A study of China and the UK. Computers in Education, 48(2), 301-317.

Mahony, K., \& Van Toen, B. (1990). Mathematical formalism as a means of occupational closure in computing-Why "hard" computing tends to exclude women. Gender and Education, 2(3), 319-331.

Margolis, J., \& Fisher, A. (2002). Unlocking the clubhouse: Women in computing. Cambridge, MA: MIT Press.

Medeiros, C.B. (2005). From subject of change to agent of change-Women and IT in Brazil. In Proceedings of the international symposium on women and IT: Creating global transformation. New York: ACM Press. 
Minguez, A.M. (2005). New technologies as social fact: Gender and digital divide in Spain in compared perspective. In Proceedings of the international symposium on women and IT: Creating global transformation. New York: ACM Press.

Moore, K., Griffiths, M., Richardson, H., \& Adam, A. (2008). Gender futures? Women, the IT workplace and stories of the future. Gender, Work and Organization, 15(5), 523-542.

Murphy, P.F., \& Elwood, J. (1998). Gendered experiences, choices and achievement-exploring the links. International Journal of Inclusive Education, 2(2), 95-118.

Murphy, P.F., \& Whitelegg, E. (2006). Girls in the classroom: A review of research on the participation of girls in Physics. London: Institute of Physics.

Nielsen, S.H., von Hellens, L.A., Greenhill, A., \& Pringle, R. (1998). Conceptualizing the influence of cultural and gender factors on student's perception of IT studies and careers. In Proceedings of the 1998 ACM SIGPR conference (pp. 86-95). New York: ACM Press.

Nielsen, Sue H., von Hellens, Liisa \& Beekhuyzen, Jenine (2005). Challenge or chaos: A discourse analysis of women's perceptions of the culture of change in the IT industry. In Issues in informing science and information technology (pp. 715-727). Brisbane, Australia: Griffith University.

Pande, R. (2006). Digital divide, gender and the Indian experience in IT. In E.M. Trauth (Ed.), Encyclopedia of gender and information technology (pp. 191199). Hershey, PA: Idea Group Reference.

Peppard, J. (1995). Broadening visions of business process re-engineering. Omega, International Journal of Management Science, 24(3), 255-270.

Pretorius, H.W., \& de Villiers, C. (2009). An analysis of the international discourse of women in Information Technology. In Proceedings of the Annual Conference of the South African Institute of Computer Scientists and Information Technologists (SAICSIT). Vereeniging, South Africa.

Quesenberry, J.L., \& Trauth, E.M. (2012). The (dis) placement of women in the IT workforce: An investigation of individual career values and organizational interventions. Information Systems Journal, 22(6), 457-473.

Ramsey, N., \& McCorduck, P. (2005). Where are the women in Information Technology? Report of Literature Search and Interviews, prepared by the Anita Borg Institute for Women and Technology for the National Centre for Women \& Information Technology University of Colorado, Boulder. (C) Anita Borg Institute for Women and Technology.

Razavi, S., \& Miller, C. (1995). From WID to GAD: Conceptual shifts in the women and development discourse. Switzerland:United Nations Research Institute for Social Development (UNRISD).

Robbins, S.P. (1993). Organizational behaviour (6th ed.). Englewood Cliffs, New Jersey: Prentice Hall International, Inc. A Simon \& Schuster Company 07632 . 
Rosser, S.V. (2005). Women in IT: Global issues and actions. In Proceedings of the International Symposium on women and IT: Creating global transformation. New York: ACM Press.

Sanders, J. (2005). Gender and technology in education: What the research tells us. In Proceedings of the International symposium on women and IT: Creating global transformation. New York: ACM Press.

Shashaani, L., \& Khalili, A. (2001). Gender and computers: Similarities and differences in Iranian college students' attitudes toward computers. Computers \& Education, 37(3-4), 41-51.

Staehr, L., Byrne, G., \& Bell, E. (2006). Gender and the Australian industry. In E.M. Trauth (Ed.), Encyclopedia of gender and information technology (pp. 467-473). Hershey, PA: Idea Group.

Statistics South Africa (STATSSA) (2012). Census 2011 in brief. Pretoria.

Trauth, E.M., \& Quesenberry, J.L. (2006). Are women an underserved community in the Information Technology profession? Paper presented at the International Conference on Information Systems, Milwaukee, WI.

Trauth, E.M., Quesenberry, J.L., \& Huang, H. (2008). A multicultural analysis of factors influencing career choice for women in the information technology workforce. Journal of Global Information Management, 16(4), 1-23.

Varma, R. (2009). Exposure, training and environment: Women's participation in computing education in the United States and India. Journal of Women and Minorities in Science and Engineering, 15(3), 205-222.

Wacjman, J. (2004). Techno feminism. Policy Press: Cambridge.

Walsham, G. (1995). The emergence of interpretivism in IS research. Information Systems Research, 6(4), 376-394.

Webber, R. (2004). Editor's comments: The rhetoric of positivism versus interpretivism: A personal view. MIS Quarterly, 28(1), iii-xii.

Webster, J. (2005). Women in IT professions: Corporate structures, masculine cultures. 3rd European symposium on gender \& IT: Working for Change, Manchester, UK.

Wodak, R. (2001). What CDA is about. In R. Wodak \& M. Meyer (Eds), Methods of critical discourse analysis (pp. 1-14). London: SAGE Publications. 